\title{
ChemComm
}

\section{Aldol reactions mediated by a tetrahedral boronate $\dagger$}

Cite this: Chem. Commun., $2013,49,361$

Received 28th September 2012, Accepted 15th November 2012

DOI: $10.1039 / \mathrm{c} 2 \mathrm{cc} 37047 f$

www.rsc.org/chemcomm

The base is a key factor in aldol reactions in organic media, determining the selectivity. Here, we describe a tetrahedral phenylboronate salt as a mild non-nucleophilic base that is able to catalyse the aldol reaction and significantly decrease the formation of undesired elimination products.

The aldol addition is an important $\mathrm{C}-\mathrm{C}$ bond forming reaction. ${ }^{1} \mathrm{~A}$ key step in the mechanism is nucleophilic attack of a deprotonated ketone (enolate) on an aldehyde to form a $\beta$-hydroxyketone. Various inorganic bases, including $\mathrm{LiOH}, \mathrm{NaOH}, \mathrm{Na}_{2} \mathrm{CO}_{3}$ and $\mathrm{Ca}(\mathrm{OH})_{2}$, have been applied for the initial deprotonation of the ketone..$^{2-5}$ However, the base catalyst is often also active in the elimination reaction, the dehydration of the $\beta$-hydroxyketone. Suppression of the aldol elimination is of great interest, as $\beta$-hydroxyketones are versatile building blocks in, for instance, the synthesis of diols, amino alcohols, lactones and polyketides. ${ }^{6-10}$

Boronates are known to mediate aldol reactions by acting both as an activator and as a template for the reactants, the ketone and the aldehyde. ${ }^{11-14}$ An interesting modification is the addition of a highly reactive trimethyl silyl enol ether to aldehydes in water with sodium dodecyl sulfate as a surfactant and diarylborinic acid $\mathbf{1}$ as the catalyst (Fig. 1). ${ }^{15}$ More recently, it was shown that the activation of the ketone as silyl enol ether is unnecessary when salt $\mathbf{2}$ as the catalyst is applied (Fig. 1). In this system, which is limited to aqueous solutions, intramolecular interaction of the neighbouring nitrogen and boron atoms stabilizes the tetrahedral boronate. Side reactions, such as dehydration, remain a problem; particularly when the reaction is favoured by stabilization of the elimination product as a result of mesomerism.

Here, we report the results of an investigation on the feasibility of the application of phenylboronate $\mathbf{4}$ as a catalyst in aldol reactions in organic media (Scheme 1). For comparison, the corresponding boronic acid 3 and the classic base sodium isopropoxide were included in this study. Compounds $\mathbf{3}$ and $\mathbf{4}$ were synthesized from

Biokatalyse \& Organische Chemie, Gebouw voor Scheikunde, Afdeling Biotechnologie, Technische Universiteit Delft, Julianalaan 136, 2628BL Delft, The Netherlands. E-mail: u.hanefeld@tudelft.nl; Fax: +31 152781415 † Electronic supplementary information (ESI) available: Material and methods; NMR and Raman spectroscopy data. See DOI: 10.1039/c2cc37047f
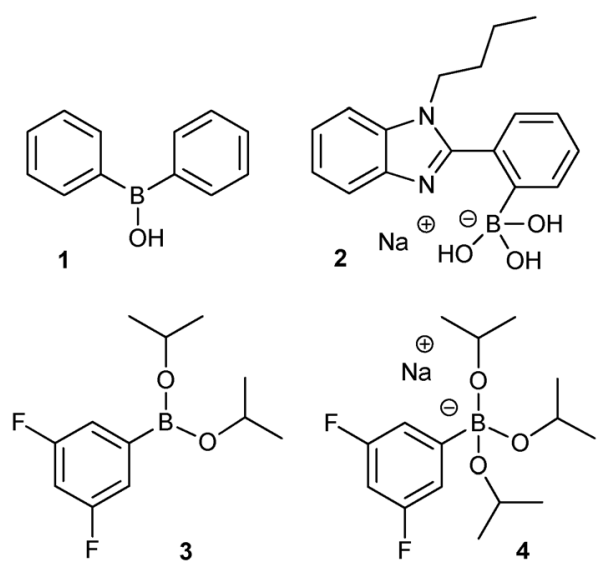

Fig. 1 Molecular structures of the boron-based catalysts discussed.

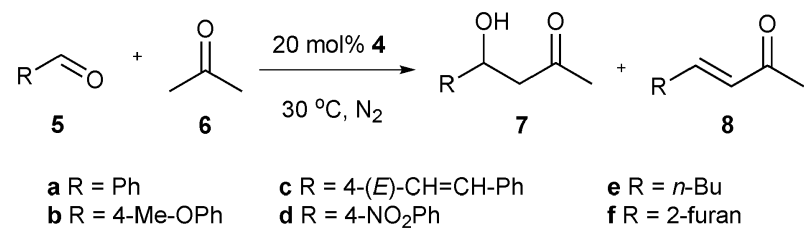

Scheme 1 The aldol reaction with a series of aldehydes and acetone.

3,5-difluorophenylboronic acid by reaction with the appropriate amount of isopropanol and sodium isopropoxide (see Scheme S1, $\mathrm{ESI} \dagger$ ) and were isolated as stable solids with a purity greater than 99\%. Both new compounds show good solubility and thermal stability in organic solvents; they did not show any dissociation as demonstrated by their characteristic ${ }^{11} \mathrm{~B}$ NMR chemical shifts for trigonal and tetragonal B-atoms, respectively (Fig. S1C and S2C, ESI; $†$ related to $\mathrm{H}_{3} \mathrm{BO}_{3}(0.1 \mathrm{M})$ at $\left.0 \mathrm{ppm}\right)$. The high stability of these B-compounds may be ascribed to the electron-withdrawing fluorosubstituents in the aromatic ring. These substituents also contribute to the high solubility of these complexes in organic solvents, which allows us to perform the aldol reaction with one of the reactants acting as solvent. In the present investigation, acetone was used as 
the solvent and the reactions were monitored by NMR and GC-MS. To rule out the possible deactivation of the catalyst (4) by water, the reaction was performed in the presence of equimolar amounts of it (relative to 4). Neither product formation nor selectivity was influenced by water.

In the presence of $\mathrm{NaO} i \mathrm{Pr}$ as the catalyst and at $30{ }^{\circ} \mathrm{C}$, benzaldehyde (5a) and an excess of acetone (6) reacted very fast to give aldol 7, which was subsequently dehydrated to $\alpha, \beta$-unsaturated ketone $\mathbf{8}$ with a lower reaction rate (Fig. $2 \mathrm{~B}$ ). The rates of both the aldol reaction and the elimination reaction appeared to be strongly dependent on the concentration of the catalyst (Table 1, entries 1-4). In addition to the elimination side product, higher molecular weight side product 9 resulting from dimerization was observed as well. Decreasing the temperature to $5{ }^{\circ} \mathrm{C}$ did not improve the selectivity towards the desired aldol product (Fig. 2B). Decreasing temperature and catalyst concentration at the same time did not inhibit the elimination reaction either (Fig. S3, ESI + ).

Trigonal B-compound 3 (up to $20 \mathrm{~mol} \%$ ) was completely inactive in the aldol reaction of $\mathbf{5 a}$ and $\mathbf{6}$, which suggests that a base is essential for the reaction to proceed. By contrast, application of tetragonal boronate 4 resulted in high conversion to the aldol within a few minutes (Table 1, entries 5-7); the reaction rate towards the aldol was about the same as that with $\mathrm{NaO} i \mathrm{Pr}$ as the catalyst, but now the subsequent elimination reaction was much slower. With 20 mol\% 4, only $8 \%$ elimination product was obtained. By decreasing the reaction temperature to $5{ }^{\circ} \mathrm{C}$, similar results were obtained (Fig. 2A). Combining $10 \mathrm{~mol} \% 4$ and $10 \mathrm{~mol} \%$ of NaOiPr resulted in full conversion of the benzaldehyde. The aldol product was formed which was dehydrated by NaOiPr to the condensation product and some higher molecular weight products resulting from dimerization (Table 1, entry 8).

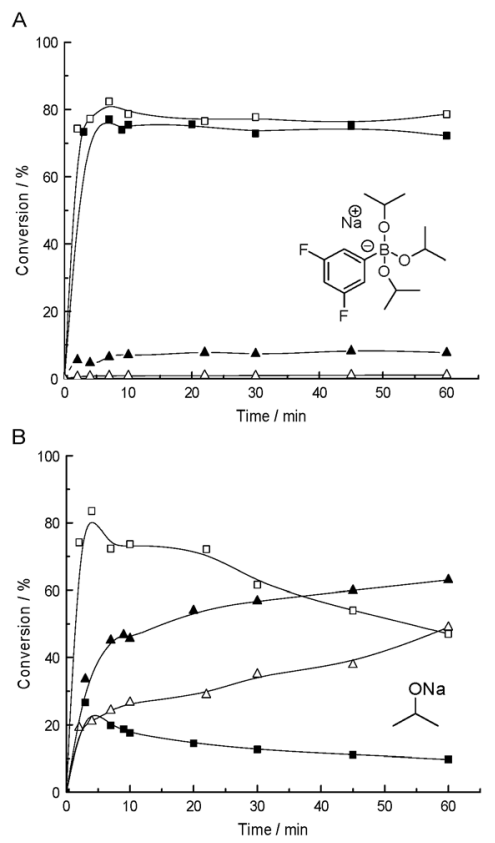

Fig. 2 Reaction between benzaldehyde and acetone, catalysed by 20 mol\% of boronate salt 4 (A) and sodium 2-propanolate (B), monitored by ${ }^{1} \mathrm{H}$ NMR at $30{ }^{\circ} \mathrm{C}$ (solid data points) and $5{ }^{\circ} \mathrm{C}$ (empty data points). The aldol and the elimination product formation is presented by squares and triangles, respectively.
Table 1 The aldol reactions of $2 \mathrm{mmol}$ of $\mathbf{5 a}$ and $20 \mathrm{mmol}$ of $\mathbf{6}$ (see Scheme 1) for $20 \mathrm{~min}$ at $30^{\circ} \mathrm{C}$. Conversions and yields are determined by ${ }^{1} \mathrm{H}$ NMR

\begin{tabular}{|c|c|c|c|c|c|}
\hline Entry & $4(\mathrm{~mol} \%)$ & $\mathrm{NaO} i \mathrm{Pr}(\mathrm{mol} \%)$ & Conv. $^{a}(\%)$ & Yield 7 (\%) & Yield $8(\%)$ \\
\hline 1 & - & 20 & $>99$ & 18 & 57 \\
\hline 2 & - & 10 & $>99$ & 23 & 55 \\
\hline 3 & - & 5 & 97 & 40 & 40 \\
\hline 4 & - & 2 & 13 & 13 & $<1$ \\
\hline 5 & 20 & - & 96 & 76 & 8 \\
\hline 6 & 10 & - & 90 & 80 & 10 \\
\hline 7 & 5 & - & 39 & 35 & 4 \\
\hline 8 & 10 & 10 & $>99$ & 11 & 45 \\
\hline
\end{tabular}

A series of aldehydes was tested in the aldol reaction in the presence of catalyst 4 (Scheme 1 and Table 2). The reactions proceeded within a few minutes with high conversions. Aromatic aldehydes and furfural, a bio-based platform chemical, all gave rise to both aldol adduct 7 and the corresponding dehydration product 8 with a high selectivity towards 7 , compared to the results obtained with the reported boron catalysts 1 and 2. ${ }^{15,16}$ The highest selectivity was obtained with aliphatic aldehyde 5e: $66 \%$ of the $\beta$-hydroxyketone $7 \mathbf{e}$ and less than $1 \%$ of the dehydration product $8 \mathrm{e}$ were formed (Table 2, entry 5). For the aromatic aldehydes conversion, selectivity to the $\beta$-hydroxyketone seems to be related to the nature of substituents and the bond delocalization. Similar lower yields and selectivities for $\mathbf{5 b}$ and $\mathbf{c}$ were observed earlier. ${ }^{15,16}$

We suggest a reaction mechanism as depicted schematically in Scheme 2. Under the reaction conditions applied, the dissociation of compound 4 towards ${ }^{-} \mathrm{O} i \mathrm{Pr}$ and corresponding $\mathbf{3}$ is negligible in acetone. This is confirmed by its ${ }^{11} \mathrm{~B}$ NMR spectrum, which shows exclusively a resonance for tetrahedral boron at around $-15.49 \mathrm{ppm}$ (Fig. S4, ESI; $\dagger$ as a standard $0.1 \mathrm{M}$ boric acid solution in $\mathrm{D}_{2} \mathrm{O}$ at 0 ppm was used). No resonance related to compound 3 was observed. Since the reaction rate of the aldol reaction, in the presence of $2 \mathrm{~mol} \% \mathrm{NaO} i \mathrm{Pr}$, is much lower than with $20 \mathrm{~mol} \% \mathbf{4}$, it is likely that undissociated $\mathbf{4}$ rather than isopropoxide is the actual catalyst in this system (Table 1, entries 4 and 5). After deprotonation of acetone by 4 , the resulting enolate exchanges with $i \mathrm{PrOH}$. The resulting tetrahedral boron-enolate $\mathbf{1 0}$ reacts with the aldehyde to form the aldol product. In the presence of $i \mathrm{PrOH}$ the aldol product 7 is released and the tetrahedral boronate $\mathbf{4}$ returns into the catalytic cycle.

The occurrence of an intermediate tetrahedral boronate with both aldehyde and acetone coordinated to the B-atom, as

Table 2 The aldol reactions of $2 \mathrm{mmol}$ of $\mathbf{5}$ and $20 \mathrm{mmol}$ of $\mathbf{6}$ (Scheme 1), catalysed by $20 \mathrm{~mol} \%$ of $\mathbf{4}$ at $30{ }^{\circ} \mathrm{C}$. Conversions and yields are determined by ${ }^{1} \mathrm{H}$ NMR

\begin{tabular}{lllllc}
\hline Entry & $\mathrm{R}$ & $t(\mathrm{~min})$ & Conv. $^{a}(\%)$ & Yield 7 $(\%)$ & Yield 8 (\%) \\
\hline $\mathbf{1}$ & $\mathbf{a}$ & 20 & 96 & 76 & 8 \\
2 & $\mathbf{b}$ & 20 & 80 & 38 & 24 \\
3 & $\mathbf{c}$ & 10 & 88 & 47 & 41 \\
4 & $\mathbf{d}$ & 5 & 95 & 52 & $<5$ \\
5 & $\mathbf{e}$ & 30 & 95 & 66 & $<1$ \\
6 & $\mathbf{f}$ & 15 & 99 & 40 & 21
\end{tabular}

${ }^{a}$ Dimerization side-product, $\mathrm{PhC}=\mathrm{C}(\mathrm{C}=\mathrm{O}) \mathrm{C}=\mathrm{CPh}(\mathbf{9})$, was detected by GC-MS. 


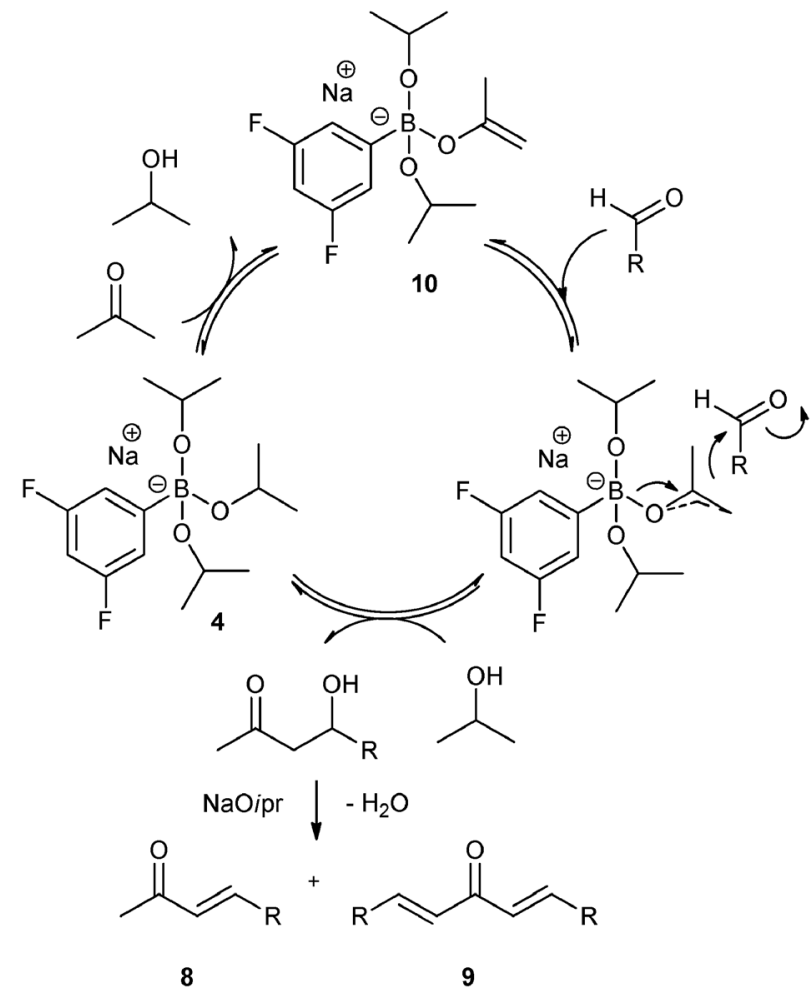

Scheme 2 Proposed mechanism for the aldol reaction catalysed by tetrahedral boronate salt 4, including the elimination reaction in the presence of a strong nucleophilic base, NaOiPr.

suggested by Evans et al. for other B-activated aldol reactions, ${ }^{11}$ is unlikely in the present case. ${ }^{11} \mathrm{~B}$ NMR spectra of a sample of $\mathbf{4}$ and benzaldehyde showed a single resonance at $-16 \mathrm{ppm}$, thus no coordination of benzaldehyde to 4 (Fig. S5, ESI; $†$ related to $0.1 \mathrm{M}$ boric acid solution in $\mathrm{D}_{2} \mathrm{O}$ at $0 \mathrm{ppm}$ ). This also rules out the mechanism, similar to Evans, suggested by Shibasaki et al. ${ }^{11}$

In contrast, acetone coordinates to tetrahedral boronate 4 , which could be confirmed by both ${ }^{11} \mathrm{~B}$ NMR and Raman spectroscopy (Fig. S6, ESI $\dagger$ ). The latter spectra demonstrate the appearance of an additional boron ester peak as a result of the interaction between 4 and acetone (solid line) compared to the spectra of $\mathbf{4}$ measured in its solid form (dashed line). Furthermore, the ${ }^{11} \mathrm{~B}$ NMR spectra (inset) show an additional resonance at around $-17.1 \mathrm{ppm}$, confirming the interaction of $\mathbf{4}$ with acetone.

In contrast ${ }^{11} \mathrm{~B}$ NMR experiments with 3 show that no tetrahedral boronate was formed due to coordination of acetone (6) or benzaldehyde (5a) to phenyl boronic ester 3 (Fig. S7, ESI $\dagger$ ). In both cases, the only observable resonance was at $8 \mathrm{ppm}$ (related to $\mathrm{H}_{3} \mathrm{BO}_{3}$ $(0.1 \mathrm{M})$ at $0 \mathrm{ppm})$ corresponding to the trigonal boronic acid ester 3 . This is in agreement with its catalytic inertness in the aldol reaction. The advantage of the designed catalytic tetrahedral boronate $\mathbf{4}$ is its steric bulkiness, which results in a reduced rate of water elimination reaction in the aldol formation compared to that when isopropoxide is applied as the base catalyst.

In conclusion, we present tetrahedral sodium triisopropyl 3,5-difluorophenylboronate (4) as a base, which can catalyse the aldol reaction. It is soluble in organic media, allowing the use of a substrate, acetone, as solvent. The reaction proceeds rapidly, with high conversion and good selectivity towards $\beta$-hydroxyketone. The tetrahedral boronate acts as a base, suitable to form boron-enolate with acetone, but is not able to dehydrate the formed aldol.

This research has been performed within the framework of the CatchBio program. The authors gratefully acknowledge the support of the Smart Mix Program of the Dutch Ministry of Economic Affairs and the Dutch Ministry of Education, Culture and Science. The authors are thankful to L. Panella (DSM), P. Alsters (DSM), J. G. de Vries (DSM), B. Kaptein (DSM), G. Kemperman (MSD) for fruitful discussions, and S.A. Kulkarni (TU Delft, P\&E/IRS) for the Raman measurements.

\section{Notes and references}

1 J. Podlech, Angew. Chem., Int. Ed., 2010, 49, 6490-6495.

2 P. S. Gradeff, US Patent, 1974, 3840601; AN 1975:43622.

3 P. W. D. Mitchell, US Patent, 1989, 4874900; AN 1989:574454.

4 K. Weissermel and H.-J. Arpe, Industrial Organic Chemistry, WileyVCH, Weinheim, 4th edn, 2003.

5 Z. Zhang, Y. W. Dong and G. W. Wang, Chem. Lett., 2003, 32, 966-967.

6 (a) S. K. Karmee and U. Hanefeld, ChemSusChem, 2011, 4, 1118-1123; (b) A. M. Frey, S. K. Karmee, K. P. de Jong, J. H. Bitter and U. Hanefeld, ChemCatChem, DOI: 10.1002/cctc.201200282.

7 R. Mestres, Green Chem., 2004, 6, 583-603.

8 J. Sukumaran and U. Hanefeld, Chem. Soc. Rev., 2005, 34, 530-542.

9 P. Clapes, W.-D. Fessner, G. A. Sprenger and A. K. Samland, Curr. Opin. Chem. Biol., 2010, 14, 154-167.

10 C. Hertweck, Angew. Chem., Int. Ed., 2009, 48, 4688-4716.

11 (a) D. A. Evans, E. Vogel and J. V. Nelson, J. Am. Chem. Soc., 1979, 101, 6120-6123; (b) T. Nitabaru, N. Kumagai and M. Shibasaki, Tetrahedron Lett., 2008, 49, 272-276; (c) T. Nitabaru, A. Nojiri, M. Kobayashi, N. Kumagai and M. Shibasaki, J. Am. Chem. Soc., 2009, 131, 13860-13869.

12 D. A. Evans, J. Bartroli and T. L. Shih, J. Am. Chem. Soc., 1981, 103, 2127-2129.

13 D. A. Evans, J. V. Nelson, E. Vogel and T. R. Taber, J. Am. Chem. Soc., 1981, 103, 3099-3111.

14 (a) G. Li, H.-X. Wei, B. S. Phelps, D. W. Purkiss and S. H. Kim, Org. Lett., 2001, 3, 823-826; (b) U. Hanefeld, A. M. Hooper and J. Staunton, Synthesis, 1999, 401-403; (c) A. Koskinen, Asymmetric Synthesis of Natural Products, John Wiley \& Sons, Chichester, 1993, pp. 69-75; (d) R. C. Harris, A. L. Cutter, K. J. Weissman, U. Hanefeld, M. C. Timoney and J. Staunton, J. Chem. Res., 1998, 283; (e) A. L. Wilkinson, U. Hanefeld, B. Wilkinson, P. F. Leadlay and J. Staunton, Tetrahedron Lett., 1998, 39, 9827-9830; $(f)$ K. J. Weissman, M. Bycroft, A. L. Cutter, U. Hanefeld, E. J. Frost, M. C. Timoney, R. Harris, S. Handa, M. Roddis, J. Staunton and P. F. Leadlay, Chem. Biol., 1998, 5, 743-754; $(g)$ C. Körner, P. Starkov and T. D. Sheppard, J. Am. Chem. Soc., 2010, 132, 5968-5969.

15 Y. Mori, J. Kobayashi, K. Manabe and S. Kobayashi, Tetrahedron, 2002, 58, 8263-8268.

16 K. Aelvoet, A. S. Batsanov, A. J. Blatch, C. Grosjean, L. G. F. Patrick, C. A. Smethurst and A. Whiting, Angew. Chem., 2008, 120, 780-782 (Angew. Chem., Int. Ed., 2008, 47, 768-770). 